\title{
Self-reported impulsivity in women with borderline personality disorder: the role of childhood maltreatment severity and emotion regulation difficulties
}

Annegret Krause-Utz ${ }^{1,2^{*}}$, Ezgi Erol ${ }^{1,2,3,4 \dagger}$, Athina V. Brousianou ${ }^{1,2+}$, Sylvia Cackowski ${ }^{4,5}$, Christian Paret ${ }^{4,5}$, Gabriele Ende ${ }^{4,6}$ and Bernet Elzinga ${ }^{1,2}$

\begin{abstract}
Background: Childhood maltreatment, such as severe emotional, physical, and sexual abuse and neglect, has been linked to impulse control problems and dysfunctional emotional coping. In borderline personality disorder (BPD), a history of childhood maltreatment may worsen difficulties in emotion regulation, which may in turn give rise to impulsive behaviours. The aim of this self-report study was to investigate associations between childhood maltreatment severity, emotion regulation difficulties, and impulsivity in women with BPD compared to healthy and clinical controls.

Methods: Sixty-one female patients with BPD, 57 clinical controls (CC, women with Attention Deficit Hyperactivity Disorder and/or Substance Use Disorder, without BPD), and 60 female healthy controls (HC) completed self-report scales on childhood trauma (Childhood Trauma Questionnaire, CTQ), difficulties in emotion regulation (Difficulties in Emotion Regulation Scale, DERS), and impulsivity (UPPS Impulsive Behaviour Scale). A conditional process analysis was performed to investigate whether emotion dysregulation statistically mediated the effect of childhood maltreatment severity on impulsivity depending on group (BPD vs. CC vs. HC).

Results: Childhood maltreatment, particularly emotional maltreatment, was positively associated with impulsivity and emotion regulation difficulties across all groups. Difficulties in emotion regulation statistically mediated the effect of childhood maltreatment on impulsivity in BPD, but not in the other groups.

Conclusion: In the context of current conceptualizations of BPD and previous research, findings suggest that problems with emotion regulation may be related to a history of childhood maltreatment, which may in turn enhance impulsivity. Targeting emotion dysregulation in psychotherapy and discussing it in relation to childhood maltreatment can help decreasing impulsive behaviors in individuals with BPD. Given the correlational design of our study which does not allow causal conclusions, future studies have to employ prospective, experimental designs and include larger sample sizes to corroborate associations between childhood maltreatment, emotion dysregulation, and impulsivity.
\end{abstract}

Keywords: Abuse and neglect, Borderline personality disorder, Emotion dysregulation, Impulsivity, Childhood trauma

\footnotetext{
* Correspondence: a.d.krause@fsw.leidenuniv.nl

${ }^{\dagger}$ Ezgi Erol and Athina V. Brousianou contributed equally to this work.

${ }^{1}$ Department of Clinical Psychology, Institute of Psychology, Leiden, The Netherlands

${ }^{2}$ Leiden Institute for Brain and Cognition (LIBC), Leiden, the Netherlands

Full list of author information is available at the end of the article
}

C The Author(s). 2019 Open Access This article is distributed under the terms of the Creative Commons Attribution 4.0 International License (http://creativecommons.org/licenses/by/4.0/), which permits unrestricted use, distribution, and reproduction in any medium, provided you give appropriate credit to the original author(s) and the source, provide a link to the Creative Commons license, and indicate if changes were made. The Creative Commons Public Domain Dedication waiver (http://creativecommons.org/publicdomain/zero/1.0/) applies to the data made available in this article, unless otherwise stated. 


\section{Introduction}

Borderline personality disorder (BPD) is a severe mental disorder, characterized by a pervasive pattern of instability in affect, cognition (i.e., self-image), interpersonal relationships, and impulsive behaviour [1].

Impulsivity and emotion dysregulation are core features of BPD [1-3]. Impulsivity in BPD can have devastating consequences, being closely linked to risky, (para)suicidal behaviour and to difficulties establishing and maintaining stable meaningful relationships [4-7]. Typical expressions of impulsivity in individuals with the disorder include substance abuse, spending sprees, gambling, reckless driving, risky sexual behaviour, sudden relationship break-ups (e.g., treatment dropout), and non-suicidal self-injury (NSSI, e.g., cutting or burning) $[3-6,8]$. These impulsive behaviours mainly occur under emotional stress [1, 3, 9-13]. Thus, impulsivity in BPD has been conceptualized as a consequence of malfunctioning emotion regulation mechanisms [2] or even as a "facet of emotional dysregulation" (Sebastian, Jacob, Lieb, \& Tüscher, p. 339) [3] rather than an expression of impulsivity as a primary trait.

One risk factor for the development of BPD is severe childhood maltreatment, such as emotional, physical, and sexual abuse, and neglect [2, 14-21]. Current conceptualizations of BPD propose that an interplay of genetic, neurobiological dispositions (e.g., increased affective sensitivity and reactivity) and stressful / traumatic life events hinders the acquisition of functional/adaptive emotional coping mechanisms, resulting in a pervasive form of emotion dysregulation, which is believed to be at the core of the disorder [7, 27]. The biosocial therory by Linehan [27] particularly emphasizes the role of an invalidating (e.g., abusive, neglectful, unstable) environment in the development of emotion dysregulation and impulsivity [2].

Specifically, this theory proposes that difficulties in emotion regulation, stemming from childhood adversities, lead to an increased use of impulsive coping strategies that help down-regulating negative emotions, i.e., that impulsivity is mainly occurring as a response to stress [2]. In line with this, there is growing evidence that deficits in impulse control (e.g., response inhibition) in BPD are substantially modulated by negative, individually salient emotions and primarily occur under stress [9-13].

A remaining research question is whether the effect of childhood maltreatment on impulsivity is mediated by emotion dysregulation and whether this is specific to BPD since emotion dysregulation and impulsivity are also core features of other mental disorders that frequently co-occur with $\mathrm{BPD}$, e.g., $\mathrm{ADHD}$ and substance use disorder.

In general, severe childhood maltreatment can have devastating consequences on the development of self-control capacities, i.e., the regulation of impulses and emotions
[22-26]. Throughout infancy, childhood, and adolescence, emotions and emotion regulation play an important role in psychosocial development [24]. Early caregiver interactions are essential in shaping healthy emotion regulatory processes, such as adaptations to changes in the environment and other social-cognitive demands [24, 25]. Children exposed to early adverse experiences are at increased risk for developing mood and anxiety disorders, probably due to changes in neurobiological systems involved in the regulation of stress and emotion, e.g., increased stress responsiveness [23]. This can have detrimental consequences across various life domains, since inhibiting strong emotions is crucial to maintaining goal-directed behaviour and self-control [26].

As mentioned above, emotion dysregulation and impulsivity are also core features of other mental disorders that frequently co-occur with BPD, such as $\mathrm{ADHD}$ [13, 28-30] and substance use disorder [30, 31]. These disorders are also associated with higher rates of childhood trauma, compared to healthy samples [31-36]. Difficulties in emotion regulation were found to statistically mediate the relationship between childhood trauma severity and substance abuse related impulsivity (e.g., problems controlling cravings) [37, 38]. Likewise, non-acceptance of emotions [39] and not being able to label emotions [40] were related to impulse control problems (e.g., relapses) in problem drinkers and higher substance use rates $[41,42]$. Although comorbidity between these disorders and BPD is high $[31,36,43]$, not all of these studies controlled for the presence of BPD which may have confounded results.

In summary, evidence suggests that childhood maltreatment is linked to difficulties in emotion regulation and impulsivity, which put individuals at higher risk for developing various psychopathologies. It is not yet entirely clear whether the effect of childhood maltreatment severity on impulsivity is statistically mediated by emotion dysregulation and whether this is more pronounced in BPD, as compared to other clinical samples. Investigating this relationship might help enhancing the understanding of impulsivity in BPD. As a first step in this direction, the present study made use of self-report data to examine the role of emotion dysregulation in the relation between childhood maltreatment and impulsivity in women with BPD compared to healthy controls and clinical controls without BPD.

Given that impulsivity is a complex heterogeneous construct $[29,30,44]$, impulsive behaviour was operationalized based on the UPPS Impulsive Behaviour model by Whiteside and Lynam [44]. This model conceptualizes impulsive behaviour as comprising multiple facets: 1) a lack of premeditation (difficulties considering the consequences of an action and making accurate plans or precautions), 2) increased sensation seeking (tendency to pursue exciting activities, openness to try 
new potentially dangerous experiences), 3) lack of perseverance (maintaining task-related attention and goal-directed behaviour in demanding situations), and 4) urgency (tendency to act without forethought during emotional states) $[44,45]$.

Based on that, the present self-report study investigated whether: 1) higher childhood maltreatment severity predicts higher impulsivity, 2) difficulties in emotion regulation statistically mediate the relationship between childhood maltreatment severity and impulsivity, and 3) this mediating relationship is particularly strong in patients with BPD, as compared to clinical controls (CC, without BPD) as well as female healthy controls.

We hypothesized that, across all participants, childhood maltreatment would positively predict emotion regulation difficulties and impulsivity. We further expected that this mediating relationship would be stronger in BPD patients compared to the other groups.

\section{Methods \\ Participants}

$N=181$ women participated. General inclusion criteria were age between 18 and 46, sufficient language proficiency, and female gender. Recruitment took place at two sites: 1) the Central Institute of Mental Health (CIMH) in Mannheim, Germany, and 2) Leiden University, the Netherlands.

Patients in the BPD group ( $n=61)$ were all recruited at the $\mathrm{CIMH}$, in the context of two larger projects designed to investigate impulsivity and provoked aggression $[28,46]$. Inclusion criterion for this group was meeting criteria for BPD according to DSM-IV [47]. Exclusion criteria were substance abuse disorder, diagnosis of Attention Deficit Hyperactivity Disorder (ADHD), lifetime history of bipolar-I affective disorder and psychotic disorder, current suicidal crisis, mental deficiency, developmental disorder, and psychotropic medication within 2 weeks prior to the study. Since participants also participated in neuroimaging research, further exclusion criteria were pregnancy and magnetic-resonance-imaging related criteria (brain injury, metal implants, left-handedness, claustrophobia). To ensure that BPD diagnosis was met and to rule out other diagnoses, interested participants were invited for an extensive diagnostic screening and intake session, including the International Personality Disorder Examination (IPDE) [48] and the Structured Clinical Interview for DSM-IV Axis-I (SCID I) [49], as described in more detail below. To assess/exclude adult ADHD diagnosis, the Wender-Reimherr Adult Attention Deficit Disorder Scale and checklists on ADHD symptoms in childhood and adulthood (["Homburger ADHS-Skalen für Erwachsene"], HASE) [50] were used (see below).

Healthy controls $(\mathrm{HC}, n=60)$ were recruited via both sites (CIMH, Leiden University). They were included if they did not have a lifetime history of mental disorders, based on the SCID and the IPDE [48, 49]. Exclusion criteria were severe somatic/neurological disorders and drug use. In addition to the SCID and IPDE, healthy controls further completed the BSL23, WURS-k; ADHD-CL, CAARS, and WRI.

Patients in the CC group $(n=57)$ were partly recruited at the CIMH and partly at Leiden University. Recruitment took place via the outpatient unit of the Department of Psychiatry at the Central Institute of Mental Health (CIMH) in Mannheim, Germany, internet platforms, and/or the research participation website of Leiden University. In Leiden, the recruitment was targeted at individuals experiencing impulse control problems related to substance (drug/alcohol) abuse. The SCID, IPDE, and Mini-International Neuropsychiatric Interview (MINI) respectively [51-53] were used for screening and diagnostic purposes. Exclusion criteria for this CC group was having a diagnosis of BPD as well as scoring higher than Mean $=1$ (15th percentile rank) on the Borderline Symptom List 23 Behaviour Checklist [54].

Major diagnoses in the CC group $(n=57)$ were substance use disorder (SUD) $(n=29, \sim 50 \%)$ and adult ADHD ( $n=28, \sim 50 \%, n=3$ with comorbid SUD); $n=17$ (30\%) had a comorbid eating disorder, $n=27(47 \%)$ had a comorbid anxiety disorder. ${ }^{1}$ The CC group showed similarly high levels of impulsivity and emotion regulation difficulties as the BPD group (see Table 1; for ADHD and SUD separately, see Additional file 2: Table S2, Additional file 3: Table S3 and Additional file 4: Table S4).

Both patient groups (BPD, CC) scored significantly higher in impulsivity and emotion regulation difficulties than HC (all $p<0.001$ ) (Table 1). Age did not differ significantly between BPD and $\mathrm{HC}$, while patients in the $\mathrm{CC}$ were significantly older than participants in the BPD group and $\mathrm{HC}(p<0.05$, see Table 1$)$. Moreover, there was a trend for differences in years of education, with patients in the BPD group and CC group showing lower education than $\mathrm{HC}(p<0.05$, see Table 1$)$. Therefore, age and education were included as statistical covariates in all analyses.

\section{Measures \\ Diagnostic instruments}

Diagnostic assessment of DSM-IV axis I disorders The Structured Clinical Interview for DSM-IV axis I disorders (SCID-I) is a semi-structured clinical interview, designed to determine DSM-IV major mental disorders, administered by trained mental health professionals. It comprises separate modules corresponding to major categories of DSM-IV diagnoses; symptoms are coded as present, subthreshold, or absent based on diagnostic algorithms. Good internal consistency, and moderate to excellent inter-rater reliability of the axis I disorders 
Table 1 Age, years of education, childhood trauma severity (CTQ sum scores), difficulties in emotion regulation (DERS sum scores), and impulsivity (UPSS Impulsive Behaviour Scale mean scores) in BPD, CC and HC

\begin{tabular}{lllll}
\hline Variable & $\begin{array}{l}\text { BPD } \\
(n=61)\end{array}$ & $\begin{array}{l}\text { CC } \\
(n=57)\end{array}$ & $\begin{array}{l}\text { HC } \\
(n=60)\end{array}$ & $\begin{array}{l}\text { Group statistics } \\
\text { (MANOVA) }\end{array}$ \\
\hline Age & $27.28 \pm 6.14^{\mathrm{a}}$ & $30.63 \pm 7.63^{\mathrm{b}}$ & $27.28 \pm 6.55^{\mathrm{a}}$ & $F_{(2,172)}=4.64, p=0.011, \eta^{2}{ }_{p}=0.05$ \\
Years of Education & $10.64 \pm 1.80^{\mathrm{a}}$ & $10.63 \pm 3.13^{\mathrm{a}}$ & $11.47 \pm 0.92^{\mathrm{b}}$ & $F_{(2,172)}=2.53, p=0.054, \eta^{2}=0.03$ \\
CTQ & $66.38 \pm 22.07^{\mathrm{a}}$ & $42.36 \pm 22.07^{\mathrm{b}}$ & $29.67 \pm 4.34^{\mathrm{c}}$ & $F_{(2,170)}=84.20, p<0.001, \eta^{2}=0.50$ \\
UPPS & $2.57 \pm 0.40^{\mathrm{a}}$ & $2.65 \pm 0.38^{\mathrm{a}}$ & $0.04 \pm 0.03^{\mathrm{b}}$ & $F_{(2,164)}=474.22, p<0.001, \eta_{p}^{2}=0.85$ \\
DERS & $97.44 \pm 2.72^{\mathrm{a}}$ & $91.52 \pm 2.80^{\mathrm{a}}$ & $69.62 \pm 2.75^{\mathrm{b}}$ & $F_{(2,170)}=28.46, p<0.001, \eta^{2} p=0.25$ \\
\hline
\end{tabular}

Table shows means \pm standard deviations of scores and results of the multivariate analysis of variance, with post-hoc Tuckey tests

BPD Borderline Personality Disorder (patient group), HC Healthy control group, CC Clinical Control group, CTQ Childhood Trauma Questionnaire, DERS Difficulties in Emotion Regulation Scale, UPPS UPPS Impulsive Behaviour Scale

Groups with different superscripts $(a, b, c)$ differ significantly at $p<0.05, \eta 2 p=$ effect size partial eta square

were reported [49]. The Mini-International Neuropsychiatric Interview (MINI) is a well-established screening tool and semi-structured interview developed for systematic diagnostic assessment of mental disorders [51]. The MINI is based on DSM-IV criteria for 17 axis I disorders. It has been found to show very good inter-rater reliability $(\alpha>.79)$, good test-retest reliability $(\alpha>.63)$, high concordance rate with other structured interviews, high patient acceptance, and very good specificity and sensitivity $[52,53]$.

SUD assessment (SCID-I, MINI) The section on Substance Use Disorder was introduced by the question "Have you ever used alcohol or taken any drugs more than once to get high, to feel better or to change your mood?". From an indicated drug category, symptoms within the past 12 month were explored (tolerance effects; withdrawal symptoms; ending up taking more drugs than attempted; failure reducing or stop taking drug, spending substantial time $(>2 \mathrm{~h})$ on obtaining, using or in recovering from drug; social, financial, legal, health and/or mental problems, e.g., from being intoxicated, high or hungover while having to fulfil responsibilities at school, at work or at home).

BPD assessment The International Personality Disorder Examination (IPDE) is a semi-structured clinical interview based on the International Classification of Diseases (ICD 10) and the DSM-III-R classification systems. Reasonably good interrater reliability and temporal stability after an interval of 6 months were reported [48]. In the current study, the IPDE was administered by trained clinicians, interrater reliability was $\mathrm{k}=0.77$. The Borderline Symptom List (BSL-23) is a self-report measure used to assess BPD symptom severity in the past week. Twenty-three statements, such as "I hated myself" and "I thought of hurting myself" are rated on a 5-point Likert scale $(0=$ not at all to $4=$ very strong). In addition, behavioural aspects related to BPD symptom severity (e.g., NSSI) in the past week are assessed. This scale previously showed high test-retest reliability $(r=0.82)$ [54]. Previously, Cronbach's $a$ for BSL-23 were found to be between 0.94 and 0.97 , denoting a high internal consistency. In the current study, Cronbach's $a$ for the BSL-23 was excellent $(\alpha=0.97)$.

ADHD assessment ("Homburger ADHS-Skalen für Erwachsene", HASE) [50]. The short version of the Wender Utah Rating Scale (WURS-k) is a self-report scale consisting of 25 items which retrospectively assess ADHD symptoms in childhood. Items are answered on a five-point Likert scale $(0=$ "not applicable" to $4=$ "applicable"). The Connor Adult ADHD Rating Scale (CAARS) and the $A D H D$-Checklist (ADHD-CL) were used to assesses symptoms of adult ADHD, based on the DSM-IV criteria for ADHD in adulthood [47]. The 66 items of the CAARS are rated on a 4-point Likert scale $(0=$ "not applicable" to $3=$ "very often"), while the 22 items of the ADHD-CL are answered on a three-point scale $(0=$ "not applicable" to $2=$ "applicable"). To verify/exclude ADHD diagnosis, the Wender-Reimherr Interview (WRI) was used, a clinical interview, based on the Wender Adult Attention Deficit Disorder Scale that is conceptualized for adult ADHD. In the current study, Cronbach's $a$ for all ADHD scales were very good to excellent (WURS-k: $a=0.89$ CAARS: $a=0.98$; ADHD-CL: $a=0.96$;)

\section{Primary measures}

Childhood Trauma Questionnaire (CTQ) Childhood maltreatment severity was assessed using the CTQ [55-57], a self-report scale with five subscales measuring emotional, sexual, and physical abuse, emotional neglect, and physical neglect ( 5 items each, overall 25 items, between $1=$ "never true" to $5=$ "very often true"). Higher scores indicate the frequency of abuse experiences. The CTQ has demonstrated good psychometric properties, with test-retest reliability ranging from .79 to .84 , internal consistency coefficients between $\alpha=.66$ and $\alpha=.94$, and good convergent validity with therapist ratings [55-58]. Cronbach's alpha in the present study suggested very good internal consistency (emotional abuse: $\alpha=.96$, physical abuse: $\alpha=.84$, sexual abuse: $\alpha=.97$, 
emotional neglect: $\alpha=.95$ ) except from the subscale physical neglect $(\alpha=.56)$.

UPPS Impulsive Behavior Scale The UPPS scale was used to assess multiple facets of impulsivity, based on the Five Factor Model of Personality [44, 45]. The scale consists of 45 items related to the four subscales Urgency (12 items; e.g., "I have trouble resisting my cravings (for food, cigarettes).", "When I feel bad, I will often do things I later regret in order to make myself feel better now."), (Lack of) premeditation (11 items; e.g., "I don't like to start a project until I know exactly how to proceed", "My thinking is usually careful and purposeful."), (Lack of) perseverance (10 items, e.g., "I generally like to see things through to the end."), and Sensation seeking (12 items; e.g., "I generally seek new and exciting experiences and sensations."). Participants rate each item on a 4 -point Likert scale $(1=$ strongly agree to $4=$ strongly disagree). Good psychometric properties have been reported, including high internal consistency ( $\alpha=.82$ to .91 ) $[44,45,59,60]$. In order to create a score for impulsivity, items for the UPPS subscales' (lack of) premeditation' and '(lack of) perseverance' were reversed, so that higher scores indicated more impulsivity. Cronbach's alpha in the present study suggested good internal consistency (Premeditation: $\alpha=.86$, Urgency: $\alpha=.89$, Sensation Seeking: $\alpha=.85)$ except from the subscale Perseverance $(\alpha=.63)$.

Difficulties in Emotion Regulation Scale (DERS) The DERS was used to assess difficulties in emotion regulation [25]. Within a multidimensional framework, the DERS assesses emotion regulation as being aware of current emotional experiences, understanding them, being able to accept and reflect on these emotions, having a clear idea about how to effectively regulate them and how to successfully use effective and mature regulation strategies [25]. The DERS consists of 36 items which reflect difficulties within each dimension of emotion regulation: ACCEPTANCE (e.g., "When I'm upset, I feel guilty for feeling that way"), STRATEGIES (e.g., "When I'm upset, I know that I can find a way to eventually feel better."), GOALS (e.g., "When I'm upset, I have difficulty getting work done"), IMPULSES / CONTROL (e.g., "I experience my emotions as overwhelming and out of control."), AWARENESS (e.g., "When I'm upset, I believe that my feelings are valid and important."), and CLARITY (e.g., "I have difficulty making sense out of my feelings"). Items are answered on a 5-point Likert scale (between $1=$ almost never and $5=$ almost always). Internal consistency of overall DERS score $(\alpha=.94)$ and subscales ( $\alpha=.80$ to .91$)$ are good, and high validity with other emotion regulation scales was reported [61]. In the present scoring version, higher scores on the DERS indicate more difficulties in emotion regulation. Internal consistency of the total scale was $\alpha=.84$.

\section{Procedure}

The study was approved by the ethical committee of the medical faculty of the University of Heidelberg in Mannheim, Germany as well as by the Psychology Ethics Committee of Leiden University. All participants were informed about the background of the study and provided informed consent, study participation could be terminated at any time point without negative consequences. Participants in the BPD and HC group completed the questionnaires (UPPS Scale, DERS, CTQ), in part as paper-pencil versions, and in part $(n=28,15 \%)$ via the online survey software Qualtrics (๔ 2015, Qualtrics, Provo, UT), which included the scales in randomized order. At the end of the study, all participants were debriefed, thanked for their participation and reimbursed (paid a small fee for their participation, 12 Euro/h).

\section{Statistical analysis}

Software IBM SPSS Statistics 22.0 with a-priori defined $\alpha$-value of $p<.05$, two-tailed, was used. Prior to all analyses, assumptions of linearity, normality of residuals, homoscedasticity and independence of residuals, and outliers (Cook's distance, Leverage values) were checked. Two extreme outliers were identified (> 3.5 SD from the mean) and removed from the analysis. Multicollinearity was checked based on VIF and tolerance values.

The hypotheses were tested using the PROCESS macro, based on principles by Hayes and Preacher $[62,63]$. Childhood maltreatment severity, represented by CTQ sum scores, was defined as predictor (X variable). Impulsivity (mean UPPS scores) as outcome variable (Y), and difficulties in emotion regulation (DERS sum score) as statistical mediator variable (M). Group (BPD, CC, HC) was conceptualized as conditional moderator variable $(\mathrm{W}){ }^{2} \mathrm{We}$ tested both the direct effect of childhood maltreatment on impulsivity (path $\mathrm{c}^{\prime}$ ) and its indirect effects through the mediator variable. Path a corresponds to the effects of the predictor variable on the statistical mediator variable, while testing for interactions with group (IE1). Path b refers to the effect of the mediator variable on the outcome variable, testing for interactions with group (IE2). The model also evaluates interactions of group with the statistical mediator variable, i.e., whether the mediating effect is significantly depending on group (IE3). Age and education were added as covariates. A bootstrapping function based on 5000 samples and a confidence interval of $95 \%$ was used to quantify effects. In separate analyses, we tested whether results changed, when testing for the four UPPS subscales separately.

The mediator (DERS total) and the dependent variable (UPPS) were significantly but only moderately moderated $(r=.360, p<.001$; for correlations between subscales see 
Additional file 5: Table S5). Due to a potential conceptual overlap between the UPPS subscale Urgency (tendency to act without forethought during emotional states) and DERS, we repeated the above-mentioned conditional mediation analyses excluding the UPPS Urgency subscale (i.e., only using the other three UPPS subscales). We further tested whether the predictor and mediator variable would interact in predicting the outcome variable, when controlling for group, which would give ground for examining moderation. The interaction effect was not significant $\left(F_{(1,168)}=0.62, p=.432\right)$.

Total effects of childhood maltreatment (without taking effects of the intervening variable and group into account - path c) were tested using multiple regression analyses (MRA) ${ }^{3}$ with UPPS scores as dependent variable, controlling for age and education. In a first step, the sum score on the CTQ was entered as predictor. In case of a significant overall effect, the CTQ subscales instead of the sum score were entered as predictors. Since multicollinearity diagnostics revealed very low tolerance values for the subscales emotional abuse and emotional neglect $(<0.24)$, means for "emotional maltreatment" (emotional abuse and neglect) and "physical maltreatment" (physical abuse and neglect) were created. Additional multiple linear regression analyses were performed to investigate the total effects of different subtypes of childhood maltreatment on DERS and DERS on impulsivity respectively.

\section{Results}

Means with standard deviation (SD) for the CTQ, DERS, and UPPS subscales and results of the MANOVAs can be found in Table 2. Patients in the BPD and CC reported higher impulsivity on all UPPS scales than HC, while CC reported significantly higher lack of premeditation than BPD (Fig. 1). On the DERS, the BPD and CC group reported higher lack of clarity, lack of regulation strategies, and more difficulties in accepting emotions than $\mathrm{HC}$, while not differing significantly from each other; levels of emotional awareness and self-perceived goal-directed behaviour were comparable across the three groups (Fig. 2). On the CTQ, BPD patients reported significantly higher levels of emotional abuse and neglect, physical abuse and neglect, and sexual abuse than the other groups; patients in the CC group reported significantly higher levels of emotional maltreatment (abuse and neglect) than HC (Fig. 3).

\section{Multiple regression analyses (total effects)}

\section{Childhood maltreatment severity and impulsivity (path c)}

The overall model was significant $\left(F_{(3,168)}=24.14, p<.0001\right.$, $R^{2}=.295, R_{(\text {adj) }}^{2}=.283$, CI: [1.903, 4.209]), with childhood maltreatment severity being a significant predictor for UPPS scores $\left(B=0.027, S E=0.004, t_{(173)}=7.56, p<.0001\right.$,
CI: $[0.020,0.034])$, while controlling for age $(B=-0.004$, $S E=0.011, t_{(173)}=0.33, p=.742$, CI: $\left.[-0.026,0.018]\right)$ and education $\left(B=-0.246, S E=0.152, t_{(173)}=2.33, p=.021, \mathrm{CI}\right.$ : $[-0.455,-0.037])$. Among the subscales, emotional maltreatment $\left(B=0.065, S E=0.010, t_{(168)}=6.40, p<.0001, \mathrm{CI}\right.$ : $[0.045,0.086])$ and physical maltreatment $(B=-0.043, S E=$ $0.019, t_{(168)}=2.26, p=.025$, CI: $\left.[-0.081,-0.010]\right)$ were significant predictors, while sexual abuse had no unique significant effect $\left(B=0.020, S E=0.017, t_{(168)}=1.18, p=.240\right.$, CI: $[-0.014,0.054])$.

\section{Childhood maltreatment severity and difficulties in emotion regulation (path a)}

The overall model was significant $\left(F_{(3,172)}=4.26, p=.006\right.$, $R^{2}=.069, R_{(\text {adj })}^{2}=.053$, CI: [89.067, 137.190]), with childhood maltreatment severity being a significant positive predictor for DERS scores $\left(B=0.221, S E=0.084, t_{(172)}=\right.$ $2.52, p=.013$, CI: $[0.046,0.377])$, while controlling for age $\left(B=0.236, S E=0.262, t_{(172)}=0.262, p=.369, \mathrm{CI}:[-0.754\right.$, $0.281])$ and education $\left(B=-5.039, S E=02.52, t_{(172)}=\right.$ $2.00, p=.047$, CI: $[-10.013,-0.065])$. Emotional maltreatment was again a unique significant predictor $(B=1.384$, $S E=0.414, t_{(172)}=3.35, p=.001, \mathrm{CI}:[0.568,2.201]$. Neither physical maltreatment $\left(B=-0.904, S E=0.778, t_{(172)}=1.16\right.$, $p=.247$, CI: $[-2.440,0.633])$ nor sexual abuse $(B=-0.248$, $\left.S E=0.410, t_{(172)}=0.61, p=.547, \mathrm{CI}:[-1.057,0.562]\right)$ were significant predictors.

\section{Difficulties in emotion regulation and impulsivity (path b)}

The underlying association between the statistical mediator variable (DERS) and outcome (impulsivity, UPPS) could also be established $\left(F_{(3,173)}=18.27, \quad p<.001, R^{2}=.241\right.$, $R_{(\text {adj })}^{2}=.227$, CI: $\left.[1.833,4.130]\right)$. More difficulties in emotion regulation predicted more impulsivity $(B=0.021, S E=$ $0.003, t_{(173)}=2.25, p<.0001$, CI: $\left.[0.015,0.028]\right)$, when controlling for age $\left(B=0.010, S E=0.011, t_{(173)}=0.86, p=.392\right.$, CI: $[-013,0.32])$, and education $(B=-0.250, S E=0.111$, $t_{(173)}=2.25, p=.025$, CI: $\left.[-0.468,-0.031]\right)$. Thus, results suggest that a statistical mediation effect may occur.

\section{Conditional mediation analysis}

The overall regression model was significant $\left(F_{(7,164)}=\right.$ $179.29, p<.0001, R^{2}=.884$ ), suggesting that approximately $88 \%$ of the variance in self-reported impulsivity (UPPS mean scores) was explained by all predictors in the model. Specifically, higher levels of childhood maltreatment severity $(B=$ $0.035, S E=0.004, t=8.26, p<.0001 ; \mathrm{CI}:[0.026,0.044])$ and more difficulties in emotion regulation $(B=0.010, S E=$ 0.003, $t=3.27, p=.001$; CI: [0.004, 0.015]) predicted more impulsivity. Group, age, and education also had significant effects, with younger age and lower education being related to higher impulsivity (age: $B=-0.013, S E=0.005, t=2.67$, $p=.008$; CI: [ $-0.022,-0.003]$; education: $B=-0.091, S E=$ $0.045, t=2.02, p=.045$; CI: $-[0.180,-0.002])$. The effect of 
Table 2 Descriptive values for scores on Impulsivity (UPPS Impulsive Behaviour Scale), Emotion Regulation Difficulties (Difficulties in Emotion Regulation Scale) and Childhood Maltreatment Severity (Childhood Trauma Questionnaire) in patients with Borderline Personality Disorder (BPD), Clinical Controls (CC) and Healthy Controls (HC) and results of the MANOVA

\begin{tabular}{|c|c|c|c|c|}
\hline Variable & $\begin{array}{l}\text { BPD } \\
(n=55)\end{array}$ & $\begin{array}{l}C C \\
(n=54)\end{array}$ & $\begin{array}{l}\mathrm{HC} \\
(n=58)\end{array}$ & Group statistics \\
\hline \multicolumn{5}{|l|}{ UPPS Impulsive Behaviour Scale } \\
\hline UPPS Negative Urgency & $2.67 \pm 0.87$ & $2.83 \pm 0.55$ & $0.22 \pm 0.06$ & $\begin{array}{l}F_{(2,164)}=350.27, p<0.001, \eta^{2} \text { (part) }=0.81 \\
B P D \text { vs. } C C:-0.17 \pm 0.11,95 \% \mathrm{Cl}[-0.43,0.10] \\
\text { BPD vs. HC: } 2.45 \pm 0.11^{* *}, 95 \% \mathrm{Cl}[2.19,2.72] \\
C C \text { vs. } H C: 2.62 \pm 0.11^{* *}, 95 \% \mathrm{Cl}[2.36,2.88]\end{array}$ \\
\hline UPPS Premeditation & $2.23 \pm 0.50$ & $2.45 \pm 0.55$ & $0.18 \pm 0.03$ & $\begin{array}{l}F_{(2,164)}=494.70, p<0.001, \eta^{2}{ }_{(\text {part })}=0.86 \\
B P D \text { vs. CC: }-0.22 \pm 0.08^{*}, 95 \% \mathrm{Cl}[-0.42,-0.03] \\
\text { BPD vs. } H C: 2.05 \pm 0.08^{* *}, 95 \% \mathrm{Cl}[1.86,2.24] \\
C C \text { vs. } H C: 2.27 \pm 0.08^{* *}, 95 \% \mathrm{Cl}[2.09,2.46]\end{array}$ \\
\hline UPPS Perseverance & $2.40 \pm 0.64$ & $2.58 \pm 0.45$ & $0.25 \pm 0.05$ & $\begin{array}{l}F_{(2,164)}=474.22, p<0.001, \eta^{2} \text { (part) }=0.85 \\
B P D \text { vs. } C C:-0.18 \pm 0.09,95 \% \mathrm{Cl}[-0.38,0.02] \\
\text { BPD vs. HC: } 2.15 \pm 0.08^{* *}, 95 \% \mathrm{Cl}[1.95,2.34] \\
C C \text { vs. } H C: 2.32 \pm 0.08^{* *}, 95 \% \mathrm{Cl}[2.12,2.52]\end{array}$ \\
\hline UPPS Sensation Seeking & $3.02 \pm 0.83$ & $2.74 \pm 0.69$ & $0.17 \pm 0.04$ & $\begin{array}{l}F_{(2,164)}=372.40, p<0.001, \eta^{2} \text { (part) }=0.82 \\
\text { BPD vs. CC: } 0.27 \pm 0.12,95 \% \mathrm{Cl}[-0.01,0.55] \\
\text { BPD vs. HC: } 2.85 \pm 0.12^{* *}, 95 \% \mathrm{Cl}[2.58,3.12] \\
\text { CC vs. } H C: 2.58 \pm 0.12^{* *}, 95 \% \mathrm{Cl}[2.30,2.85]\end{array}$ \\
\hline \multicolumn{5}{|c|}{ Difficulties in Emotion Regulation Scale } \\
\hline DERS Clarity & $12.60 \pm 4.81$ & $12.81 \pm 4.87$ & $8.12 \pm 2.58$ & $\begin{array}{l}F_{(2,164)}=22.66, p<0.001, \eta^{2} \text { (part) }=0.22 \\
B P D \text { vs. } C C:-0.21 \pm 0.80,95 \% \mathrm{Cl}[-2.12,1.69] \\
\text { BPD vs. HC: } 4.48 \pm 0.79^{* * * *}, 95 \% \mathrm{Cl}[2.61,6.35] \\
C C \text { vs. } H C: 4.69 \pm 0.79^{* * *}, 95 \% \mathrm{Cl}[2.82,6.57]\end{array}$ \\
\hline DERS Regulation strategies & $21.89 \pm 8.03$ & $21.30 \pm 7.09$ & $11.84 \pm 3.80$ & $\begin{array}{l}F_{(2,164)}=42.45, p<0.001, \eta^{2}{ }_{(\text {part })}=0.34 \\
\text { BPD vs. CC: } 0.59 \pm 1.25,95 \% \mathrm{Cl}[-2.36,3.55] \\
\text { BPD vs. HC: } 10.05 \pm 1.23^{* * *}, 95 \% \mathrm{Cl}[7.14,12.95] \\
\text { CC vs. HC: } 9.45 \pm 1.23^{* * *}, 95 \% \mathrm{Cl}[6.54,12.37]\end{array}$ \\
\hline DERS Awareness & $16.25 \pm 4.96$ & $15.53 \pm 3.62$ & $16.88 \pm 3.62$ & $\begin{array}{l}F_{(2,164)}=1.49, p=0.23, \eta^{2} \text { (part) }=0.02 \\
B P D \text { vs. } C C: 0.72 \pm 0.79,95 \% \mathrm{Cl}[-1.14,2.58] \\
B P D \text { vs. } H C:-0.62 \pm 0.77,95 \% \mathrm{Cl}[-2.45,1.20] \\
C C \text { vs. } H C:-1.34 \pm 0.78,95 \% \mathrm{Cl}[-3.18,0.50]\end{array}$ \\
\hline DERS Control & $18.05 \pm 5.35$ & $14.41 \pm 5.30$ & $11.09 \pm 2.81$ & $\begin{array}{l}F_{(2,164)}=32.28, p<0.001, \eta^{2} \text { (part) }=0.28 \\
\text { BPD vs. CC: } 3.65 \pm 0.88^{* * *^{\prime \prime}}, 95 \% \mathrm{Cl}[1.56,5.74] \\
\text { BPD vs. HC: } 6.97 \pm 0.87^{* * * *^{\prime *}}, 95 \% \mathrm{Cl}[4.92,9.02] \\
C C \text { vs. } H C: 3.32 \pm 0.87^{* *}, 95 \% \mathrm{Cl}[1.26,5.38]\end{array}$ \\
\hline DERS Goals & $12.04 \pm 5.66$ & $12.69 \pm 4.94$ & $11.33 \pm 4.25$ & $\begin{array}{l}F_{(2,164)}=1.04, p=0.35, \eta^{2}(\text { part) }=0.01 \\
B P D \text { vs. } C C:-0.65 \pm 0.95,95 \% \mathrm{Cl}[-2.90,1.60] \\
B P D \text { vs. } H C: 0.71 \pm 0.94,95 \% \mathrm{Cl}[-1.51,2.92] \\
C C \text { vs. } H C: 1.36 \pm 0.94,95 \% \mathrm{Cl}[-0.87,3.58]\end{array}$ \\
\hline DERS Acceptance & $16.35 \pm 6.76$ & $15.56 \pm 6.52$ & $10.36 \pm 3.40$ & $\begin{array}{l}F_{(2,164)}=18.31, p<0.001, \eta^{2} \text { (part) }=0.18 \\
\text { BPD vs. CC: } 0.79 \pm 1.10,95 \% \mathrm{Cl}[-1.80,3.38] \\
\text { BPD vs. } H C: 5.98 \pm 1.08^{* * * *}, 95 \% \mathrm{Cl}[3.43,8.53] \\
C C \text { vs. } H C: 5.19 \pm 1.08^{* * *}, 95 \% \mathrm{Cl}[2.63,7.75]\end{array}$ \\
\hline \multicolumn{5}{|l|}{ Childhood Trauma Questionnaire } \\
\hline CTQ Emotional Abuse & $17.53 \pm 6.12$ & $10.46 \pm 5.11$ & $5.95 \pm 1.28$ & $\begin{array}{l}F_{(2,164)}=89.80, p<0.001, \eta^{2}{ }_{\text {(part) }}=0.52 \\
\text { BPD vs. CC: } 7.06 \pm 0.88^{*}, 95 \% \mathrm{Cl}[-4.97,9.16] \\
\text { BPD vs. HC: } 11.58 \pm 0.87^{*}, 95 \% \mathrm{Cl}[9.52,13.63] \\
\text { CC vs. HC: } 4.51 \pm 0.87^{*}, 95 \% \mathrm{Cl}[2.45,6.58]\end{array}$ \\
\hline CTQ Emotional Neglect & $17.45 \pm 5.86$ & $11.70 \pm 4.91$ & $6.95 \pm 2.37$ & $\begin{array}{l}F_{(2,164)}=74.14, p<0.001, \eta^{2}{ }_{\text {(part) }}=0.48 \\
\text { BPD vs. CC: } 5.75 \pm 0.88^{*}, 95 \% \mathrm{Cl}[-3.67,7.83] \\
\text { BPD vs. HC: } 10.51 \pm 0.86^{*}, 95 \% \mathrm{Cl}[8.46,12.55] \\
C C \text { vs. } H C: 4.76 \pm 0.87^{*}, 95 \% \mathrm{Cl}[2.70,6.81]\end{array}$ \\
\hline CTQ Physical Abuse & $9.85 \pm 5.09$ & $6.59 \pm 2.87$ & $5.16 \pm 0.62$ & $\begin{array}{l}F_{(2,164)}=28.72, p<0.001, \eta^{2} \text { (part) }=0.26 \\
\text { BPD vs. CC: } 3.26 \pm 0.64^{*}, 95 \% \mathrm{Cl}[1.74,4.79] \\
\text { BPD vs. } H C: 4.70 \pm 0.63^{*}, 95 \% \mathrm{Cl}[3.20,6.20] \\
C C \text { vs. } H C: 1.44 \pm 0.64,95 \% \mathrm{Cl}[-0.07,2.94]\end{array}$ \\
\hline CTQ Physical Neglect & $10.49 \pm 3.88$ & $6.98 \pm 2.57$ & $6.29 \pm 1.75$ & $F_{(2,164)}=34.63, p<0.001, \eta_{(\text {part })}^{2}=0.30$ \\
\hline
\end{tabular}


Table 2 Descriptive values for scores on Impulsivity (UPPS Impulsive Behaviour Scale), Emotion Regulation Difficulties (Difficulties in Emotion Regulation Scale) and Childhood Maltreatment Severity (Childhood Trauma Questionnaire) in patients with Borderline Personality Disorder (BPD), Clinical Controls (CC) and Healthy Controls (HC) and results of the MANOVA (Continued)

\begin{tabular}{|c|c|c|c|c|}
\hline Variable & $\begin{array}{l}\text { BPD } \\
(n=55)\end{array}$ & $\begin{array}{l}\text { CC } \\
(n=54)\end{array}$ & $\begin{array}{l}\mathrm{HC} \\
(n=58)\end{array}$ & Group statistics \\
\hline & & & & $\begin{array}{l}\text { BPD vs. CC: } 3.51 \pm 0.55^{*}, 95 \% \mathrm{Cl}[2.22,4.80] \\
\text { BPD vs. } H C: 4.20 \pm 0.54^{*}, 95 \% \mathrm{Cl}[2.93,5.47] \\
\text { CC vs. HC: } 0.69 \pm 0.54,95 \% \mathrm{Cl}[-0.59,1.97]\end{array}$ \\
\hline CTQ Sexual Abuse & $11.55 \pm 6.62$ & $6.78 \pm 4.03$ & $5.33 \pm 1.23$ & $\begin{array}{l}F_{(2,164)}=29.24, p<0.001, \eta^{2} \text { (part) }=0.26 \\
\text { BPD vs. CC: } 4.77 \pm 0.86^{*}, 95 \% \mathrm{Cl}[2.73,6.81] \\
\text { BPD vs. } H C: 6.22 \pm 0.85^{*}, 95 \% \mathrm{Cl}[4.22,8.22] \\
\text { CC vs. } H C: 1.45 \pm 0.85,95 \% \mathrm{Cl}[-0.56,3.46]\end{array}$ \\
\hline
\end{tabular}

Table shows means \pm standard deviations of scores and results of the multivariate analysis of variance, with post-hoc Tuckey tests BPD Borderline Personality Disorder (patient group), CC Clinical Control group consisting by ADHD and SUD, CTQ Childhood Trauma Questionnaire, DERS Difficulties in Emotion Regulation Scale, HC Healthy control group, UPPS UPPS Impulsive Behaviour Scale ${ }^{*} p<0.05,{ }^{* *} p<0.01,{ }^{* * *} p<0.001$

group was also significant $(B=2.070, S E=0.185, t=$ 11.16, $p<.0001$; CI: [1.70, 2.434]).

There was a significant interaction of childhood maltreatment severity and group on impulsivity $(B=0.017$, $S E=0.004, t=2.67, p<.0001$; CI: [0.024, 0.010]). Within the three groups, childhood maltreatment severity positively predicted impulsivity in BPD (Rho $=.232, p=.037$, $\left.\mathrm{R}^{2}=.05\right)$ but not in HC and ADHD $(p>.05)$, see Fig. 4. The interaction between group and childhood trauma in predicting DERS was not significant $(B=0.019, S E=0.188$, $t=0.10, p=.917$; CI: [ $0.392,0.352]$; CTQ: $B=0.154, S E=$ $0.212, t=0.72, p=.471$; CI: [- 0.266, 0.573]).

There was a significant interaction between DERS and group $(B=-0.005, S E=0.002, t=4.61, p=.032$; CI: $[-0.010,-0.0004])$. Furthermore, there was a conditional effect of group regarding the effect of childhood maltreatment through difficulties in emotion regulation on impulsivity: Based on the bootstrapping confidence interval, difficulties in emotion regulation statistically mediated the effect of childhood trauma on impulsivity in the BPD group ( $B=0.001, S E=0.001, \mathrm{CI}$ : [0.001, 0.002]) but not in the other groups (HC: $B=0.001, S E=0.002$, CI: $[-0.002,0.006] ; C C: B=0.0001, S E=0.001, C I$ : $[-0.004,0.002])$. As shown in Fig. 5, in the BPD group, childhood trauma had a significant effect on DERS (path a), which in turn significantly predicted impulsivity (path b). The total effect of childhood maltreatment on impulsivity was significant, while this link was not significant anymore, when controlling for DERS in the regression model.

Analyses for the four UPPS subscales separately revealed similar results. Analyses without the UPPS subscale Urgency revealed the same results (see Additional file 6).

\section{Discussion}

This self-report study aimed at investigating the effect of childhood maltreatment severity on impulsivity and whether

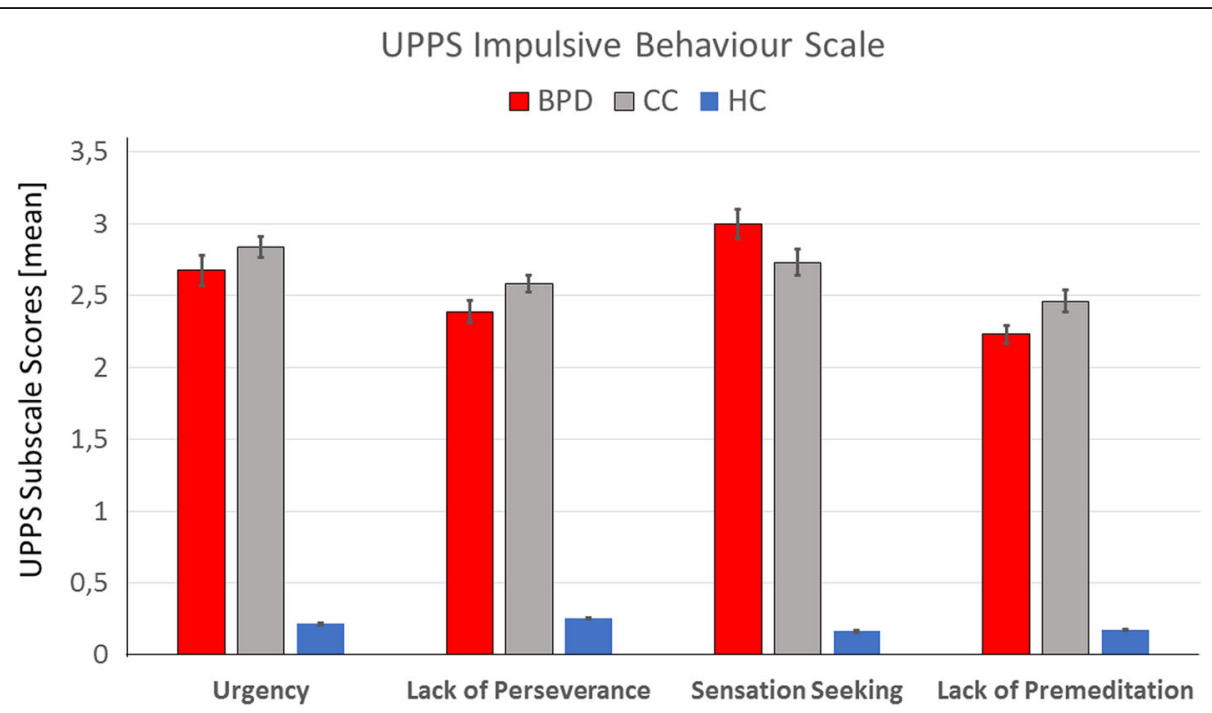

Fig. 1 This figure shows means with standard errors of the mean for scores on the UPPS Impulsive Behaviour Scale in patients with Borderline Personality Disorder (BPD), Clinical Controls (CC) and Healthy Controls (HC) as well as results of the MANOVA 


\section{Difficulties in Emotion Regulation Scale}

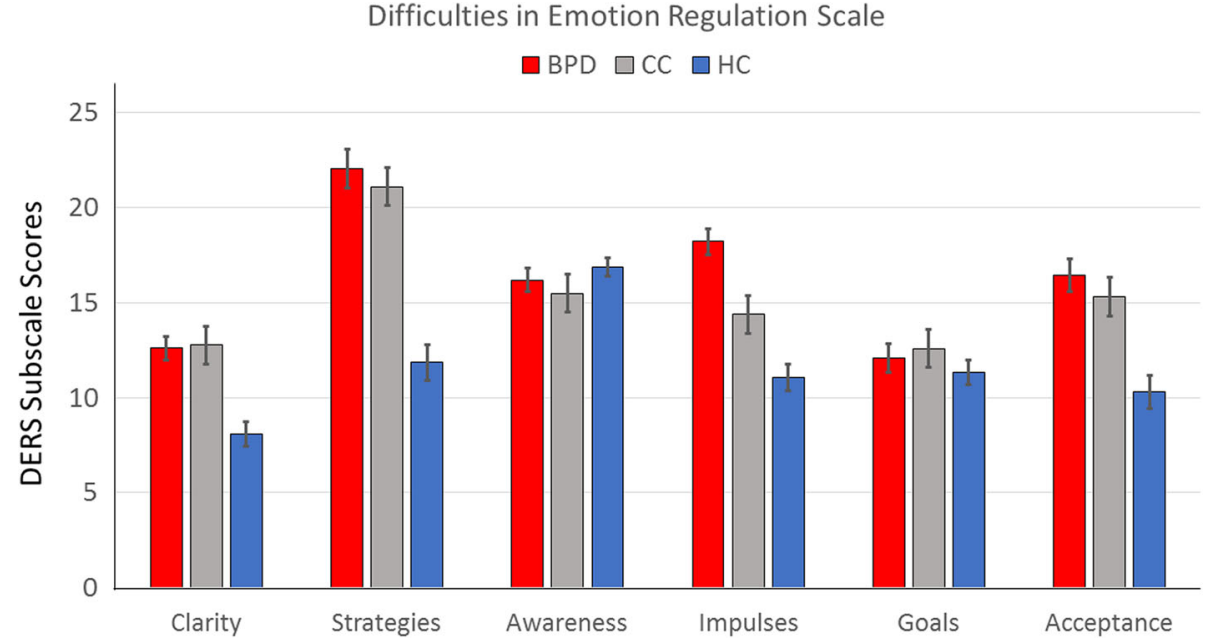

Fig. 2 This figure shows means with standard errors of the mean for scores on the Difficulties in Emotion Regulation Scale (DERS) in patients with Borderline Personality Disorder (BPD), Clinical Controls (CC) and Healthy Controls (HC) as well as results of the MANOVA

difficulties in emotion regulation statistically mediated this relationship in BPD compared to healthy controls and clinical controls. Higher childhood maltreatment severity, particularly emotional maltreatment, predicted more difficulties in emotion regulation and impulsivity across all groups. There was a significant interaction effect of childhood maltreatment and group in predicting impulsivity: The effect of childhood maltreatment severity on impulsivity was significantly more pronounced in BPD than in $\mathrm{HC}$ and ADHD. Moreover, a significant statistical mediation effect was found, depending on group: In the BPD group, the effect of childhood maltreatment on impulsivity in BPD was not significant anymore, when controlling for difficulties in emotion regulation.
The positive association between childhood maltreatment severity, difficulties in emotion regulation, and impulsivity is in line with our hypothesis and previous research [14-21, 32-38]. Childhood maltreatment can have devastating effects on the development of healthy and adaptive emotion regulation and self-control, e.g., the ability to tolerate intense negative emotions, considering the results of one's actions, and to focus on goal-directed behaviour when in a negative state [22, 23].

Among the different types of childhood maltreatment, emotional maltreatment was the only significant predictor for both emotion regulation difficulties and impulsivity. Emotional maltreatment is considered a particularly chronic and detrimental form of abuse. This may involve humiliating

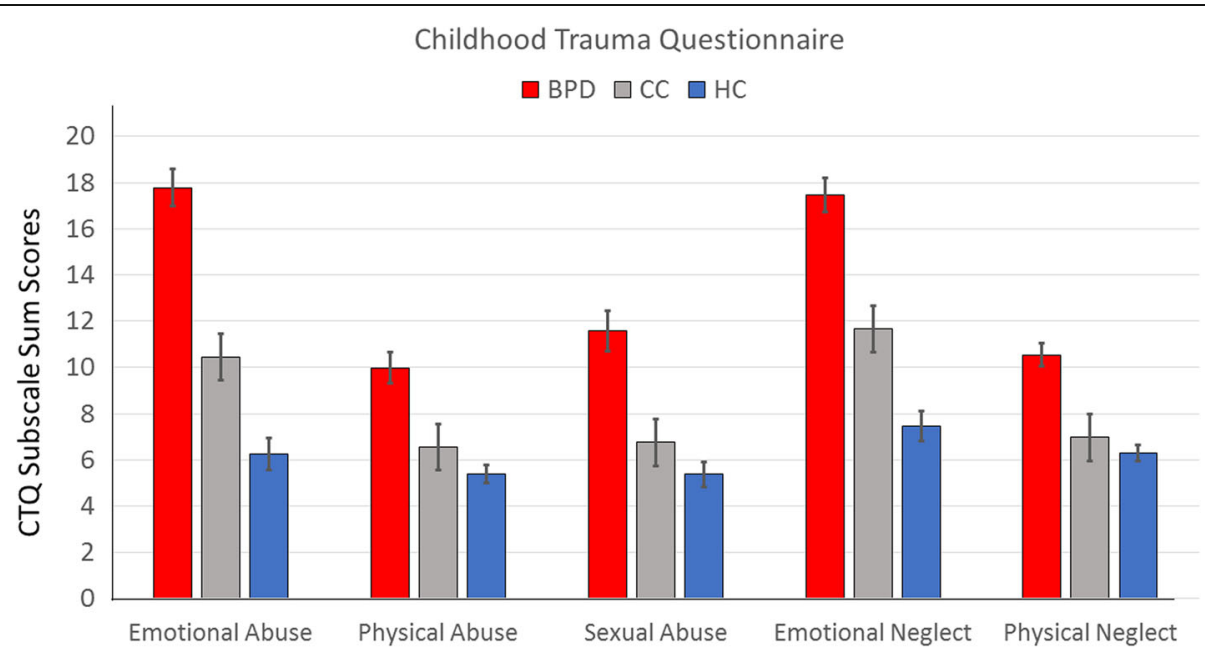

Fig. 3 This figure shows means with standard errors of the mean for scores on the Childhood Trauma Questionnaire (CTQ) in patients with Borderline Personality Disorder (BPD), Clinical Controls (CC) and Healthy Controls (HC) as well as results of the MANOVA 


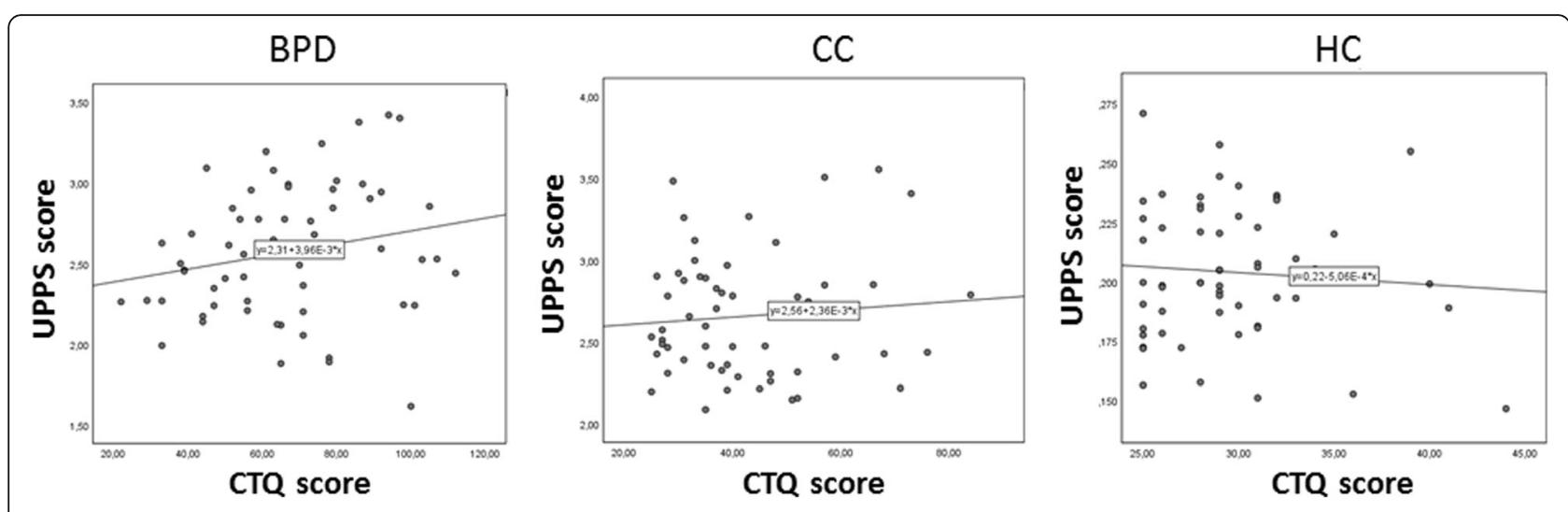

Fig. 4 This scatterplot illustrates correlations between scores on the Childhood Trauma Questionnaire (CTQ) and scores on the UPPS Impulsive Behaviour Scale in patients with Borderline Personality Disorder (BPD), Clinical Controls (CC) and Healthy Controls (HC)

or demeaning behaviour toward the child, psychological unavailability of caretakers (e.g., due to illness) and a failure to meet children's basic emotional and psychological needs often a consequence of the parent's own unresolved childhood adversities [64-68]. A history of emotional maltreatment has been directly linked to alterations in emotional processing, including increased affect intensity and decreased distress tolerance [64-67]. Among different forms of child maltreatment, emotional abuse was the strongest predictor of emotion regulation difficulties later in life [66]. In particular, previous studies in BPD found that emotional maltreatment (emotional abuse and neglect) was the strongest predictor for malfunctioning emotion regulation strategies [68] and BPD symptom severity [20, 68], when controlling for other types of abuse [20,68].

Further in line with previous studies, we found higher rates of childhood maltreatment in the BPD group compared to the other groups [14-21] as well as in the clinical control group compared to healthy controls [32-38]. The finding of higher childhood maltreatment rates in BPD is consistent with previous research; e.g., in the large-scale multicenter Collaborative Longitudinal Personality Disorders Study, higher rates of self-reported childhood abuse and neglect were found in individuals with BPD than in other personality disorders [15]. Moreover, among four groups of personality disorder (schizotypal, borderline, avoidant, and obsessivecompulsive), and a major depression comparison group, BPD participants reported the highest rate of traumatic exposure (particularly to sexual traumas, including childhood sexual abuse and being physically attacked), and youngest age of first traumatic event [21].

Interestingly, the effect of childhood maltreatment severity on impulsivity was significantly more pronounced in BPD than in the control groups. While a history of

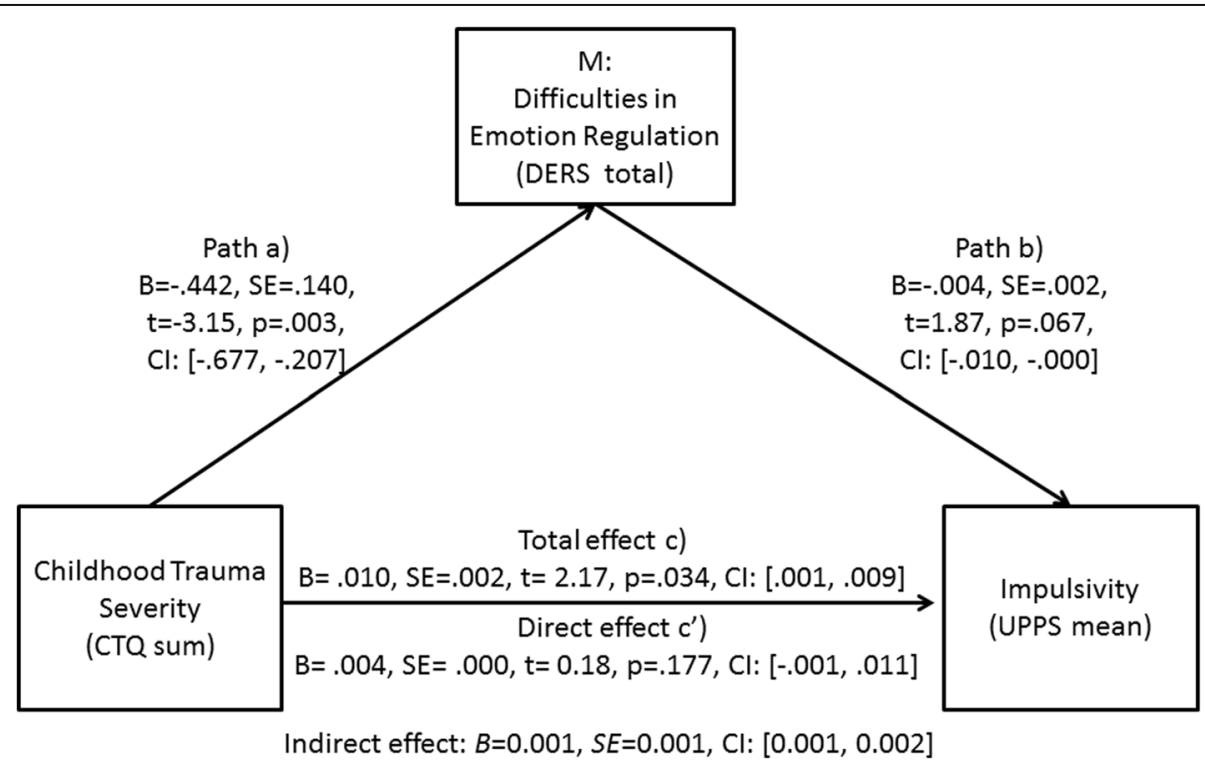

Fig. 5 This Figure summarizes the effect of the mediation analysis in the group of Borderline Personality Disorder (BPD) patients 
trauma is neither necessary nor sufficient for the etiology of BPD, childhood abuse, especially emotional and sexual abuse, was found to aggravate BPD symptomatology. This is in line with the biosocial theory by Linehan [27] and current conceptualizations of BPD highlighting the role of an invalidating or traumatic environment in the etiology of the disorder [2]. At the same time, childhood maltreatment may put individuals at higher risk for developing other psychopathologies, such as ADHD and SUD, which frequently co-occur with BPD [32-38].

In the present study, emotion regulation difficulties statistically mediated the relationship between childhood maltreatment severity and impulsivity in BPD, but not in the other groups. Since impulsive behaviour in BPD mainly occurs under emotional distress [9-12], it has been conceptualized as a consequence or facet of malfunctioning emotion regulation mechanisms $[2,3]$. In previous research, stress-dependent increases in impulsivity were found in BPD but not in adults with Attention Deficit Hyperactivity Disorder (ADHD) [9, 11]. In line with this and in the context of other previous experimental and neurobiological research [9-13], our findings suggest that difficulties in emotion regulation may underlie self-perceived impulsive behaviour in BPD.

While the inclusion of well-characterized patient groups and the exclusion of mutual comorbidity between the groups (i.e., BPD, SUD/ADHD) is a clear strength of our study, this strict recruitment restricted our samples sizes, which may have limited the statistical power to detect effects, especially in smaller subsamples (ADHD, SUD patients). While we only included women, further research should also include male participants. Since the cross-sectional correlational design of our study does not allow causal conclusions, prospective and longitudinal studies with larger samples are required to gain more insights into causal relationships. In particular, to replicate the statistical mediation effect observed in our study and to identify a directional, potentially causal link, studies with experimental and/or repeated-measure data are needed, in which the independent variable precedes the dependent variable in time. This is of particular importance since mediation analyses with cross-sectional data can lead to an over-estimation of effects [69]. Likewise, the use of self-reports generally involves the risk of potential biases, such as social desirability, limited awareness and insight, different subjective interpretations of measured concepts, and/or a 'coloring' of reports by current mood [70]. Childhood maltreatment was assessed in a retrospective and subjective manner which is particularly prone to recall biases. It is possible that individuals with BPD may suffer from more traumatic re-experiencing, associated with more vivid negative memories, and may consequently recall childhood experiences more negatively or have a tendency to report more negative childhood adversities.
Previous research suggests that there self-reports and behavioural or psychophysiological measures of emotion regulation and impulsivity in BPD are only weakly or not at all correlated [29-31]. Therefore, future research should additionally use experimental tasks of emotion regulation (e.g., cognitive reappraisal task), impulsivity (e.g., Go/ NoGo tasks, stop signal tasks, or delay discounting task) and emotional distress (e.g., experimental psychosocial stressor tasks) [9-13], preferably combining multiple measures (self-reports, behavioural tasks, psychophysiological measures such as heart rate or skin conductance, neuroimaging) at different assessments points.

Including a control group of healthy participants who had been exposed to severe childhood maltreatment without having developed a mental disorder would help corroborating associations between childhood maltreatment, emotion dysregulation, and impulsivity. In general, a full factorial design, with additional control groups for high versus low levels of childhood maltreatment in $\mathrm{HC}$ as well as BPD and CC would allow a better investigation of the impact of childhood adversities on impulsivity (and interactions with mental disorders such as BPD). Future research may take the duration and onset of childhood trauma into account to further extend our findings.

A remaining research question is to which degree different components of emotion regulation and multiple facets of impulsivity overlap or can be disentangled from each other. In a previous study, we showed that deficits in action withholding / response inhibition (Go/NoGo task) were influenced by acute experimental stress, while delay discounting was a more stable feature in BPD [11]. To identity common and distinct components of impulsivity in relation to emotion regulation in BPD, ADHD, and SUD, future research might employ network analyses, aimed at visualizing inter-relations (node strengths centrality) between factors in a pre-defined model. For instance, this method might help addressing the centrality of factors, such as childhood adversities, emotion dysregulation, and impulsivity, and their place in a network, i.e., how distinct and/or connected these factors are in predicting BPD severity [71].

Since positive urgency (acting impulsively while experiencing extreme positive affect) was not assessed in our study, future research should investigate this factor of impulsivity in more detail. Likewise, the DERS mainly focuses on negative feelings of emotional distress. Typical expressions of impulsivity in BPD, such as gambling, substance abuse, promiscuity, or risky sexual activities, may not only serve reducing negative feelings but also increasing positive feelings (e.g., joy, excitement, belonging), which can have devastating consequences on physical/mental health and across different life domains (work, relationships, etc.).

More research is needed to replicate our novel findings and to gain deeper insight into other factors (e.g., 
positive emotions) that may contribute to impulsivity in BPD.

\section{Conclusion}

In conclusion, our findings point to a significant association between childhood maltreatment severity, difficulties in emotion regulation, and impulsivity in BPD. Emotion dysregulation was found to underlie self-perceived impulsive behaviour in BPD. Strengthening emotion regulation strategies, especially in interpersonal contexts, is a main focus of evidence-based BPD treatments, such as Dialectical Behavioural Therapy [27], Mentalization-Based Therapy [72], Transference-focused psychotherapy [73], and Schema Therapy [74]. In combination with emotion regulation training, addressing the consequences of childhood adversities (e.g., using psychoeducation to highlight associations with stress tolerance and impulsivity) and integrating traumatic experiences into autobiographical memory (e.g., exposure-based treatment in combination with skills training and stabilizing interventions) might help to reduce impulsive behaviour, such as self-harm and suicidal attempts, in BPD.

\section{Endnotes}

${ }^{1}$ We decided to not split the CC group into subgroups of patients with ADHD and SUD, because these subsamples were too small to perform a meaningful group comparison and regression analysis. ADHD and SUD did not differ significantly in age (Additional file 1: Table S1) and ACE (Additional file 2: Table S2) and together showed similarly high levels of impulsivity and emotion regulation difficulties as the BPD group.

${ }^{2}$ In Process model 59, there is no option for multi-categorical variables. Therefore, the analysis was re-run with changed group labels, which ensured that results were robust.

${ }^{3}$ In Process model 59, there is no option for a total effect model, therefore separate MRAs were performed.

\section{Additional files}

Additional file 1: Table S1. Demographic characteristics of patients with Borderline Personality Disorder (BPD), subgroups of patients with Attention Deficit Hyperactivity Disorder (ADHD) and Substance Use Disorder (SUD) and Healthy Controls (HC). (DOCX $19 \mathrm{~kb}$ )

Additional file 2: Table S2. Descriptive values and results of the MANOVA for the Childhood Trauma Questionnaire (CTQ) in patients with Borderline Personality Disorder (BPD), subgroups of patients with Attention Deficit Hyperactivity Disorder (ADHD) and Substance Use Disorder (SUD) and Healthy Controls (HC). (DOCX $21 \mathrm{~kb}$ )

Additional file 3: Table S3. Descriptive values and results of the MANOVA for the UPPS Impulsive Behaviour Scale in patients with Borderline Personality Disorder (BPD), subgroups of patients with Attention Deficit Hyperactivity Disorder (ADHD) and Substance Use Disorder (SUD) and Healthy Controls (HC). (DOCX $20 \mathrm{~kb})$

Additional file 4: Table S4. Descriptive values and results of the MANOVA for the Difficulties in Emotion Regulation Scale (DERS) in patients with Borderline Personality Disorder (BPD), subgroups of patients with Attention Deficit Hyperactivity Disorder (ADHD) and Substance Use Disorder (SUD) and Healthy Controls (HC). (DOCX $22 \mathrm{~kb}$ )

Additional file 5: Table S5. Correlations between Scores on the scales. (DOCX $24 \mathrm{~kb}$ )

Additional file 6: Conditional process analysis without the subscale Urgency. (DOCX 13 kb)

Acknowledgements

We thank all participants of this study for their essential contribution.

\section{Funding}

The project was partly funded by a grant of the German Research Foundation (Deutsche Forschungs Gemeinschaft, DFG, grant number: SCHM 1526/13-1, EN 361/12-1).

\section{Availability of data and materials}

The datasets used and/or analysed during the current study are available from the corresponding author on reasonable request.

\section{Authors' contributions}

$A K-U, E E, A V B$, and $B E$ designed the study and drafted the first version of the paper. SC, EE, AK-U, and CP contributed to data collection. AK-U, EE, AVB, and $B E$ discussed statistical analyses. AK-U and BE provided supervision throughout each stage of writing. SC, CP, and GE provided in depth feedback that contributed to the final version of the paper, which has been approved by all authors.

\section{Ethics approval and consent to participate}

This study has been approved by the Ethics Committee of the Medical Faculty Mannheim of Heidelberg University in 2011 as well as by the Psychology Ethics Committee of Leiden University in 2016 (CEP16-1219/381). All participants were informed about the background of the study and provided informed consent, study participation could be terminated at any time point without negative consequences.

\section{Consent for publication}

Not applicable.

Competing interests

The authors declare that they have no competing interests.

\section{Publisher's Note}

Springer Nature remains neutral with regard to jurisdictional claims in published maps and institutional affiliations.

\section{Author details}

'Department of Clinical Psychology, Institute of Psychology, Leiden, The Netherlands. ${ }^{2}$ Leiden Institute for Brain and Cognition (LIBC), Leiden, the Netherlands. ${ }^{3}$ Institute of Psychiatric and Psychosomatic Psychotherapy, Central Institute of Mental Health, Mannheim, Germany. ${ }^{4}$ Medical Faculty, University of Heidelberg, Mannheim, Germany. ${ }^{5}$ Department of

Psychosomatic Medicine and Psychtherapy, Central Institute of Mental Health (CIMH), Mannheim, Germany. ${ }^{\circ}$ Department Neuoimaging, Central Institute of Mental Health $(\mathrm{CIMH})$, Mannheim, Germany.

Received: 25 October 2018 Accepted: 5 February 2019 Published online: 05 March 2019

\section{References}

1. APA. Diagnostic and statistical manual of mental disorders: DSM-5. Washington, DC: American Psychiatric Association; 2013.

2. Crowell SE, Beauchaine TP, Linehan MM. A biosocial developmental model of borderline personality: elaborating and extending linehan's theory. Psychol Bull. 2009;135(3):495-510.

3. Sebastian A, Jacob G, Lieb K, Tüscher O. Impulsivity in borderline personality disorder: a matter of disturbed impulse control or a facet of emotional dysregulation? Curr Psychiatry Rep. 2013;15(2):339. 
4. Brown MZ, Comtois KA, Linehan MM. Reasons for suicide attempts and nonsuicidal self-injury in women with borderline personality disorder. J Abnorm Psychol. 2002;111(1):198.

5. Chapman AL, Dixon-Gordon KL. Emotional antecedents and consequences of deliberate self-harm and suicide attempts. Suicide Life Threat Behav. 2007:37(5):543-52

6. Plener PL, Schumacher TS, Munz LM, Groschwitz RC. The longitudinal course of non-suicidal self-injury and deliberate self-harm: a systematic review of the literature. Borderline Personal Disord Emot Dysregul. 2015;2(1): 2. https://doi.org/10.1186/s40479-014-0024-3.

7. Schmahl C, Herpertz SC, Bertsch K, Ende G, Flor H, Kirsch P, et al. Mechanisms of disturbed emotion processing and social interaction in borderline personality disorder: state of knowledge and research agenda of the German clinical research unit. Borderline Personal Disord Emot Dysregul. 2014;1(1):12.

8. Chapman AL, Leung DW, Lynch TR. Impulsivity and emotion dysregulation in borderline personality disorder. J Personal Disord. 2008;22(2):148-64

9. Cackowski S, Reitz AC, Ende G, Kleindienst N, Bohus M, Schmahl C, et al. Impact of stress on different components of impulsivity in borderline personality disorder. Psychol Med. 2014;44(15):3329-40.

10. Cackowski S, Krause-Utz A, Van Eijk J, Klohr K, Daffner S, Sobanski E, et al. Anger and aggression in borderline personality disorder and attention deficit hyperactivity disorder-does stress matter? Borderline Personal Disord Emot Dysregul. 2017:4(1):6.

11. Krause-Utz A, Cackowski S, Daffner S, Sobanski E, Plichta MM, Bohus M, et al. Delay discounting and response disinhibition under acute experimental stress in women with borderline personality disorder and adult attention deficit hyperactivity disorder. Psychol Med. 2016;46(15):3137-49.

12. Krause-Utz A, Sobanski E, Alm B, Valerius G, Kleindienst N, Bohus M, et al. Impulsivity in relation to stress in patients with borderline personality disorder with and without co-occurring attention-deficit/hyperactivity disorder: an exploratory study. J Nerv Ment Dis. 2013;201(2):116-23.

13. Sebastian A, Jung $P$, Krause-Utz A, Lieb K, Schmahl C, Tüscher O. Frontal dysfunctions of impulse control-a systematic review in borderline personality disorder and attention-deficit/hyperactivity disorder. Front Hum Neurosci. 2014;8:698.

14. Ball JS, Links P. Borderline personality disorder and childhood trauma: evidence for a causal relationship. Cur Psych Rep. 2009;11(1):63-8.

15. Battle CL, Shea MT, Johnson DM, Yen S, Zlotnick C, Zanarini MC, et al. Childhood maltreatment associated with adult personality disorders: findings from the collaborative longitudinal personality disorders study. J Personal Disord. 2004;18(2):193-211.

16. Bandelow B, Krause J, Wedekind D, Broocks A, Hajak G, Rüther E. Early traumatic life events, parental attitudes, family history, and birth risk factors in patients with borderline personality disorder and healthy controls. Psychiatry Res. 2005;134(2):169-79.

17. Golier JA, Yehuda R, Bierer LM, Mitropoulou V, New AS, Schmeidler J, et al. The relationship of borderline personality disorder to posttraumatic stress disorder and traumatic events. Am J Psychiatry. 2003;160(11):2018-24.

18. Herman JL, Perry C, Van der Kolk BA. Childhood trauma in borderline personality disorder. Am J Psychiatry. 1989;146(4):490-5.

19. Maclntosh HB, Godbout N, Dubash N. Borderline personality disorder: disorder of trauma or personality, a review of the empirical literature. Can Psychol. 2015;56(2):227-41.

20. Pietrek C, Elbert T, Weierstall R, Müller O, Rockstroh B. Childhood adversities in relation to psychiatric disorders. Psychiatry Res. 2013;206(1):103-10.

21. Yen S, Shea MT, Battle CL, Johnson DM, Zlotnick C, Dolan-Sewell R, et al. Traumatic exposure and posttraumatic stress disorder in borderline, schizotypal, avoidant, and obsessive-compulsive personality disorders: fingings from the collaborative longitudinal personality disorders study. J Nerv Ment Dis. 2002;190(8):510-8.

22. Gilbert R, Widom CS, Browne K, Fergusson D, Webb E, Janson S. Burden and consequences of child maltreatment in high-income countries. Lancet. 2009;373(9657):68-81.

23. Heim C, Nemeroff CB. The role of childhood trauma in the neurobiology of mood and anxiety disorders: preclinical and clinical studies. Biol Psychiatry. 2001;49(12):1023-39

24. Thompson RA. Emotion and emotion regulation: two sides of the developing coin. Emot Rev. 2011;3(1):53-61.

25. Gratz K, Roemer L. Multidimensional assessment of emotion regulation and dysregulation: development, factor structure, and initial validation of the difficulties in emotion regulation scale. J Psychopathol Behav Assess. 2004; 26(1):41-54.
26. Tice DM, Bratslavsky E, Baumeister RF. Emotional distress regulation takes precedence over impulse control: if you feel bad, do it! J Pers Soc Psychol. 2001;80(1):53.

27. Linehan MM. Cognitive-behavioral treatment of borderline personality disorder. New York, NY: The Guilford Press; 1993.

28. Ende G, Cackowski S, Van Eijk J, Sack M, Demirakca T, Kleindienst N, et al. Impulsivity and aggression in female BPD and ADHD patients: association with ACC glutamate and GABA concentrations. Neuropsychopharmacology. 2016;41(2):410.

29. Stahl C, Voss A, Schmitz F, Nuszbaum M, Tüscher O, Lieb K, et al. Behavioral components of impulsivity. J Exp Psychol Gen. 2014;143(2):850-86.

30. Moeller FG, Barratt ES, Dougherty DM, Schmitz JM, Swann AC. Psychiatric aspects of impulsivity. Am J Psychiatry. 2001;158(11):1783-93.

31. Bornovalova MA, Lejuez CW, Daughters SB, Rosenthal MZ, Lynch TR. Impulsivity as a common process across borderline personality and substance use disorders. Clin Psychol Rev. 2005;25(6):790-812.

32. Douglas KR, Chan G, Gelernter J, Arias AJ, Anton RF, Weiss RD, et al. Adverse childhood events as risk factors for substance dependence: partial mediation by mood and anxiety disorders. Addict Behav. 2010;35(1):7-13.

33. Huang MC, Schwandt ML, Ramchandani VA, George DT, Heilig M. Impact of multiple types of childhood trauma exposure on risk of psychiatric comorbidity among alcoholic inpatients. Alcohol Clin Exp Res. 2012;36(6):1099-107.

34. Evren C, Kural S, Cakmak D. Clinical correlates of childhood abuse and neglect in substance dependents. Addict Behav. 2006;31(3):475-85.

35. Daigre C, Rodríguez-Cintas L, Tarifa N, Rodríguez-Martos L, Grau-López L, Berenguer $M$, et al. History of sexual, emotional or physical abuse and psychiatric comorbidity in substance-dependent patients. Psychiatry Res. 2015:229(3):743-9.

36. Matthies SD, Philipsen A. Common ground in attention deficit hyperactivity disorder (ADHD) and borderline personality disorder (BPD)-review of recent findings. Borderline Personal Disord Emot Dysregul. 2014;1(1):3.

37. Wardell JD, Strang NM, Hendershot CS. Negative urgency mediates the relationship between childhood maltreatment and problems with alcohol and cannabis in late adolescence. Addict Behav. 2016;56:1-7.

38. Banducci AN, Hoffman EM, Lejuez CW, Koenen KC. The impact of childhood abuse on inpatient substance users: specific links with risky sex, aggression, and emotion dysregulation. Child Abuse Negl. 2014;38(5):928-38.

39. Dvorak RD, Sargent EM, Kilwein TM, Stevenson BL, Kuvaas NJ, et al. Alcohol use and alcohol-related consequences: associations with emotion regulation difficulties. Am J Drug Alcohol Abuse. 2014;40(2):125-30.

40. Veilleux JC, Skinner KD, Reese ED, Shaver JA. Negative affect intensity influences drinking to cope through facets of emotion dysregulation. Personal Individ Differ. 2014:59:96-101.

41. Bonnet A, Bréjard V, Pedinielli JL. Emotional dispositions and substance use: mediating effect of alexithymia. Psychol Rep. 2013;112(1):289-302.

42. Fox HC, Axelrod SR, Paliwal P, Sleeper J, Sinha R. Difficulties in emotion regulation and impulse control during cocaine abstinence. Drug Alcohol Depend. 2007:89(2-3):298-301.

43. Distel MA, Carlier A, Middeldorp CM, Derom CA, Lubke GH, Boomsma DI. Borderline personality traits and adult attention-deficit hyperactivity disorder symptoms: a genetic analysis of comorbidity. Am J Med Genet B Neuropsychiatr Genet. 2011;156(7):817-25.

44. Whiteside SP, Lynam DR. The five factor model and impulsivity: using a structural model of personality to understand impulsivity. Pers Individ Dif. 2001;30(4):669-89.

45. Whiteside SP, Lynam DR, Miller JD, Reynolds SK. Validation of the UPPS impulsive behavior scale: a four-factor model of impulsivity. Eur J Personal. 2005;19:559-74

46. Paret C, Hoesterey S, Kleindienst N, Schmahl C. Associations of emotional arousal, dissociation and symptom severity with operant conditioning in borderline personality disorder. Psychiatry Res. 2016;244:194-201. https://doi. org/10.1016/j.psychres.2016.07.054.

47. APA. Diagnostic and statistical manual of mental disorders, DSM-IV-TR (4th ed., text rev.). Washington, DC: American Psychiatric Publishing; 2000.

48. Loranger AW. International Personality Disorder Examination (IPDE); DSM-IV and ICD-10 modules. Odessa: Psychological Assessment Resources; 1999.

49. First MB, Spitzer RL, Gibbon M, Williams JBW. Structured clinical interview for DSM-IV Axis I Disorders, Clinician Version (SCID-CV). Washington, D.C.: American Psychiatric Press, Inc.; 1996.

50. Rösler M, Retz-Junginger MP, Retz W, Stieglitz RD. Homburger ADHS-Skalen für Erwachsene (HASE). Göttingen: Hogrefe; 2008. 
51. Lecrubier Y, Sheehan DV, Weiller E, Amorim P, Bonora I, Sheehan KH, et al. The Mini International Neuropsychiatric Interview (MINI). A short diagnostic structured interview: reliability and validity according to the CIDI. Eur J Psychiatry. 1997;12(5):224-31.

52. Hergueta T, Baker R, Dunbar GC. The Mini-International Neuropsychiatric Interview (MINI): the development and validation of a structured diagnostic psychiatric interview for DSM-IV and ICD-10. J Clin Psychiatry. 1998;59(Suppl 20):22-33.

53. Pinninti NR, Madison H, Musser E, Rissmiller D. MINI international neuropsychiatric schedule: clinical utility and patient acceptance. Eur Psychiatry. 2003;18(7):361-4.

54. Bohus M, Kleindienst N, Limberger MF, Stieglitz RD, Domsalla M, Chapman $\mathrm{AL}$, et al. The short version of the Borderline Symptom List (BSL-23): development and initial data on psychometric properties. Psychopathology. 2009:42(1):32-9.

55. Bernstein DP, Fink L. Childhood trauma questionnaire. A retrospective selfreport manual. San Antonio: The Psychological Corporation, Harcourt Brace \& Company; 1998

56. Bernstein DP, Ahluvalia T, Pogge D, Handelsman L. Validity of the childhood trauma questionnaire in an adolescent psychiatric population. J Am Acad Child Adolesc Psychiatry. 1997;36(3):340-8.

57. Bernstein DP, Fink L, Handelsman L, Foote J, Lovejoy M, Wenzel K, et al. Initial reliability and validity of a new retrospective measure of child abuse and neglect. Am J Psychiatry. 1994;151(8):1132-6.

58. Bernstein DP, Stein JA, Handelsman L. Predicting personality pathology among adult patients with substance use disorders: effects of childhood maltreatment. Addict Behav. 1998;23(6):855-68.

59. Miller J, Flory K, Lynam D, Leukefeld C. A test of the four-factor model of impulsivity-related traits. Pers Individ Dif. 2003;34(8):1403-18.

60. Magid V, Colder CR. The UPPS impulsive behavior scale: factor structure and associations with college drinking. Personal Individ Differ. 2007:43(7):1927-37.

61. Bardeen JR, Fergus TA, Orcutt HK. An examination of the latent structure of the difficulties in emotion regulation scale. J Psychopathol Behav Assess. 2012;34(3):382-92.

62. Hayes AF, Preacher KJ. Statistical mediation analysis with a multicategorical independent variable. Br J Math Stat Psychol. 2014;67(3):451-70. https://doi. org/10.1111/bmsp. 12028

63. Hayes AF. Introduction to mediation, moderation, and conditional process analysis -a regression-based approach. New York: The Guilford Press; 2013.

64. Bifulco A, Moran PM, Baines R, Bunn A, Stanford K. Exploring psychological abuse in childhood: II. Association with other abuse and adult clinical depression. Bull Menn Clin. 2002;66(3):241-58.

65. Spinhoven P, Elzinga BM, Van Hemert A, de Rooij M, Penninx BW. Childhood maltreatment, maladaptive personality types and level and course of psychological distress: a six-year longitudinal study. J Affect Disord. 2016;191:100-8.

66. Burns EE, Jackson JL, Harding HG. Child maltreatment, emotion regulation, and posttraumatic stress: the impact of emotional abuse. J Aggress Maltreat Trauma. 2010;19(8):801-19.

67. van Harmelen AL, de Jong PJ, Glashouwer KA, Spinhoven P, Penninx BW, Elzinga BM. Child abuse and negative explicit and automatic selfassociations: the cognitive scars of emotional maltreatment. Behav Res Ther. 2010;48(6):486-94.

68. Carvalho Fernando S, Beblo T, Schlosser N, Terfehr K, Otte C, Löwe B, et al. The impact of self-reported childhood trauma on emotion regulation in borderline personality disorder and major depression. J Trauma Dissociation. 2014;15(4):384-401.

69. Maxwell SE, Cole DA. Bias in cross-sectional analyses of longitudinal mediation. Psychol Methods. 2007;12(1):23-44.

70. Baker AJ. Adult recall of childhood psychological maltreatment: definitional strategies and challenges. Child Youth Serv Rev. 2009;31(7):703-14.

71. Fried El, Cramer AOJ. Moving forward: challenges and directions for psychopathological network theory and methodology. Perspect Psychol Sci. 2017;12(6):999-1020.

72. Bateman A, Fonagy P. Mentalization based treatment for borderline personality disorder. World Psychiatry. 2010;9(1):11-5.

73. Yeomans FE, Clarkin JF, Kernberg OF. Transference-focused psychotherapy for borderline personality disorder: a clinical guide (First edition). Washington, District of Columbia and London: American Psychiatric Publishing; 2015

74. Young JE. Cognitive therapy for personality disorders: a schema-focused approach. Sarasota, FL, England; 1990.

Ready to submit your research? Choose BMC and benefit from:

- fast, convenient online submission

- thorough peer review by experienced researchers in your field

- rapid publication on acceptance

- support for research data, including large and complex data types

- gold Open Access which fosters wider collaboration and increased citations

- maximum visibility for your research: over $100 \mathrm{M}$ website views per year

At BMC, research is always in progress.

Learn more biomedcentral.com/submissions 